\title{
The Impact of Primary Tumor Location in Synchronous Metastatic Colorectal Cancer: Differences in Metastatic Sites and Survival
}

\author{
Nelleke P. M. Brouwer, Bsc ${ }^{1}$, Dave E. W. van der Kruijssen, $\mathrm{MD}^{2}$, Niek Hugen, $\mathrm{MD}, \mathrm{PhD}^{1}$, \\ Ignace H. J. T. de Hingh, $\mathrm{MD}^{3}$, Iris D. Nagtegaal, $\mathrm{MD}^{4}$, Rob H. A. Verhoeven, $\mathrm{PhD}^{1,5}$, Miriam Koopman, $\mathrm{MD}^{2}$, and \\ Johannes H. W. de Wilt, MD ${ }^{1}$ \\ ${ }^{1}$ Department of Surgery, Radboud University Medical Center, Nijmegen, The Netherlands; ${ }^{2}$ Department of Medical \\ Oncology, University Medical Center Utrecht, Utrecht, The Netherlands; ${ }^{3}$ Department of Surgery, Catharina Hospital \\ Eindhoven, Eindhoven, The Netherlands; ${ }^{4}$ Department of Pathology, Radboud University Medical Center, Nijmegen, \\ The Netherlands; ${ }^{5}$ Department of Research, Netherlands Comprehensive Cancer Organization (IKNL), Utrecht, \\ The Netherlands
}

\begin{abstract}
Purpose. We explored differences in survival between primary tumor locations, hereby focusing on the role of metastatic sites in synchronous metastatic colorectal cancer (mCRC).

Methods. Data for patients diagnosed with synchronous mCRC between 1989 and 2014 were retrieved from the Netherlands Cancer registry. Relative survival and relative excess risks (RER) were analyzed by primary tumor location (right colon (RCC), left colon (LCC), and rectum). Metastatic sites were reported per primary tumor location. Survival was analyzed for metastatic sites combined and for single metastatic sites.

Results. In total, 36,297 patients were included in this study. Metastatic sites differed significantly between primary tumor locations, with liver-only metastases in $43 \%$, $54 \%$, and $52 \%$ of RCC, LCC, and rectal cancer patients respectively $(p<0.001)$. Peritoneal metastases were most prevalent in RCC patients (33\%), and lung metastases were most prevalent in rectal cancer patients $(28 \%)$. Regardless of the location of metastases, patients with RCC had a worse survival compared with LCC (RER 0.81, 95\% CI 0.78-0.83) and rectal cancer (RER 0.73, 95\% CI
\end{abstract}

(C) The Author(s) 2019

First Received: 4 September 2019;

Published Online: 2 December 2019

N. P. M. Brouwer, Bsc

e-mail: nelleke.brouwer@radboudumc.nl
0.71-0.76). The survival disadvantage for RCC remained present, even in cases with metastasectomy for liver-only disease (LCC: RER 0.66, 95\% CI 0.57-0.76; rectal cancer: RER 0.84, 95\% CI 0.66-1.06).

Conclusions. This study showed significant differences in relative survival between primary tumor locations in synchronous mCRC, which can only be partially explained by distinct metastatic sites. Our findings support the concept that RCC, LCC and rectal cancer should be considered distinct entities in synchronous mCRC.

Colorectal cancer (CRC) is the third most common cancer in the world. ${ }^{1}$. Approximately $25 \%$ of the patients present with synchronous metastatic colorectal cancer (mCRC). ${ }^{2}$ In a time span of 25 years, the relative survival of both early-stage colorectal cancer and mCRC has improved. The 5-year relative survival of mCRC increased from 4 to $12 \%$, mainly due to intensified and more effective treatment. ${ }^{3}$

Primary tumor location in CRC has prognostic value, suggesting that right-sided colon (RCC), left-sided colon (LCC), and rectal cancer can be regarded as different entities. Population-based studies found that patients with metastasized LCC had better survival compared with patients with metastasized RCC and demonstrated that in recent years patients with metastasized rectal cancer had a better survival than patients with metastasized colon cancer. ${ }^{2,4}$

There are several explanations for the differences in prognosis between primary tumor locations: (1) poorer response to systemic therapy of patients with RCC patients 
compared with patients with LCC; (2) higher frequency of signet-ring cell carcinoma and mucinous adenocarcinoma in RCC, which are associated with worse outcome; and (3) differences in metastatic patterns, which might influence survival as well. ${ }^{5-10}$

The purpose of this study was to explore the differences in survival between primary tumor location in mCRC, hereby focusing on the role of metastatic sites using data from the Netherlands Cancer Registry.

\section{METHODS}

\section{Patient and Data Collection}

Data were retrieved from the Netherlands Cancer Registry (NCR), which collects data of all patients with newly diagnosed malignancies in the Netherlands since 1989. Trained registrars gather data on tumor and treatment characteristics, after notification from the pathology departments of hospitals, all taking part in the automated pathology archive (PALGA), and the National Registry of Hospital Discharge Diagnoses. Primary tumor characteristics were coded according to International Classification of Diseases for Oncology (ICD-O) and the TNM (tumornode-metastasis) classification, using the edition valid at time of cancer diagnosis. ${ }^{11,12}$

All CRC patients who were diagnosed between 1989 and 2014 with distant metastases at the time of diagnosis (i.e., synchronous metastases) were selected. Synchronous metastases were defined as distant metastases of primary CRC in other organs, excluding regional lymph nodes, detected by imaging or histological techniques previous to the start of treatment. Anatomical sites of metastases were registered according to the ICD-O. Since 2008, the registration of metastases was fully implemented in all regions in the Netherlands. Patients with unknown site of
TABLE 1 Patient/tumor characteristics for synchronous mCRC, stratified to primary tumor location

\begin{tabular}{|c|c|c|c|c|c|}
\hline & \multicolumn{3}{|c|}{ Primary tumor location } & \multirow{2}{*}{$\begin{array}{l}\text { Total } \\
(N=36,297)\end{array}$} & \multirow[t]{2}{*}{$p$ value $\left(\chi^{2}\right)$} \\
\hline & $\begin{array}{l}\text { Right colon } \\
(N=12,889)\end{array}$ & $\begin{array}{l}\text { Left colon } \\
(N=14,355)\end{array}$ & $\begin{array}{l}\text { Rectum } \\
(N=9053)\end{array}$ & & \\
\hline \multicolumn{6}{|l|}{ Gender } \\
\hline Male & $6252(49)$ & $8311(58)$ & $5612(62)$ & $20,175(56)$ & \\
\hline Female & $6637(51)$ & $6044(42)$ & $3441(38)$ & $16,122(44)$ & $<0.001$ \\
\hline \multicolumn{6}{|l|}{ Age-category } \\
\hline$<45$ & $352(3)$ & $509(4)$ & $371(4)$ & $1232(3)$ & \\
\hline $45-59$ & 2215 (17) & $2954(21)$ & $2152(24)$ & $7321(20)$ & \\
\hline $60-74$ & $5795(45)$ & $6667(46)$ & $4129(46)$ & $16,591(46)$ & \\
\hline$\geq 75$ & $4527(35)$ & $4225(29)$ & $2401(27)$ & $11,153(31)$ & $<0.001$ \\
\hline \multicolumn{6}{|l|}{ Histology } \\
\hline Adenocarcinoma & $10,364(80)$ & $12,748(89)$ & $8368(92)$ & $31,480(87)$ & \\
\hline Mucinous adenocarcinoma & 2114 (16) & $1398(10)$ & $586(6)$ & $4098(11)$ & \\
\hline Signet ring cell carcinoma & $411(3)$ & 209 (1) & $99(1)$ & $719(2)$ & $<0.001$ \\
\hline \multicolumn{6}{|l|}{ T-stage } \\
\hline (y)pT0-2 & 277 (4) & $409(5)$ & $411(12)$ & $1097(6)$ & \\
\hline (y)pT3-4 & $7233(94)$ & $7986(94)$ & $2.791(84)$ & $18,010(92)$ & \\
\hline (y)pT unknown & $148(2)$ & 107 (1) & $115(3)$ & $370(2)$ & $<0.001$ \\
\hline \multicolumn{6}{|l|}{$\mathrm{N}$-stage } \\
\hline (y)pN0 & $1272(17)$ & $1806(21)$ & $867(25)$ & $3945(20)$ & \\
\hline (y)pN1-2 & $5861(76)$ & $6104(72)$ & $2293(67)$ & $14,258(73)$ & \\
\hline (y)pN unknown & $529(7)$ & $608(7)$ & $267(8)$ & $1404(7)$ & $<0.001$ \\
\hline \multicolumn{6}{|l|}{ Number of metastatic sites } \\
\hline 1 & $8517(66)$ & 9979 (70) & $6293(70)$ & $24,789(68)$ & $<0.001$ \\
\hline$\geq 2$ & $4372(34)$ & $4376(30)$ & $2760(30)$ & $11,508(32)$ & \\
\hline \multicolumn{6}{|l|}{ Treatment } \\
\hline Resection primary tumor & $7686(60)$ & $8524(59)$ & $3443(38)$ & $19,653(54)$ & $<0.001$ \\
\hline Chemotherapy & $6375(49)$ & $7589(53)$ & $4930(54)$ & $18,894(52)$ & $<0.001$ \\
\hline Radiotherapy & $81(1)$ & $376(3)$ & $3719(41)$ & $4176(12)$ & $<0.001$ \\
\hline Metastasectomy & 1398 & $1863(13)$ & $1434(16)$ & 4695 (13) & $<0.001$ \\
\hline
\end{tabular}


FIG. 1 Metastatic spread to different organs according to primary tumor location.

la Overall prevalence of metastatic sites. b Prevalence of single metastatic sites (i.e., no metastasis detected elsewhere).

The differences in frequencies of metastatic sites between primary tumor sites were statistically significant, $p<0.001)$ in the $\chi^{2}$ test
(A)

$100 \%$

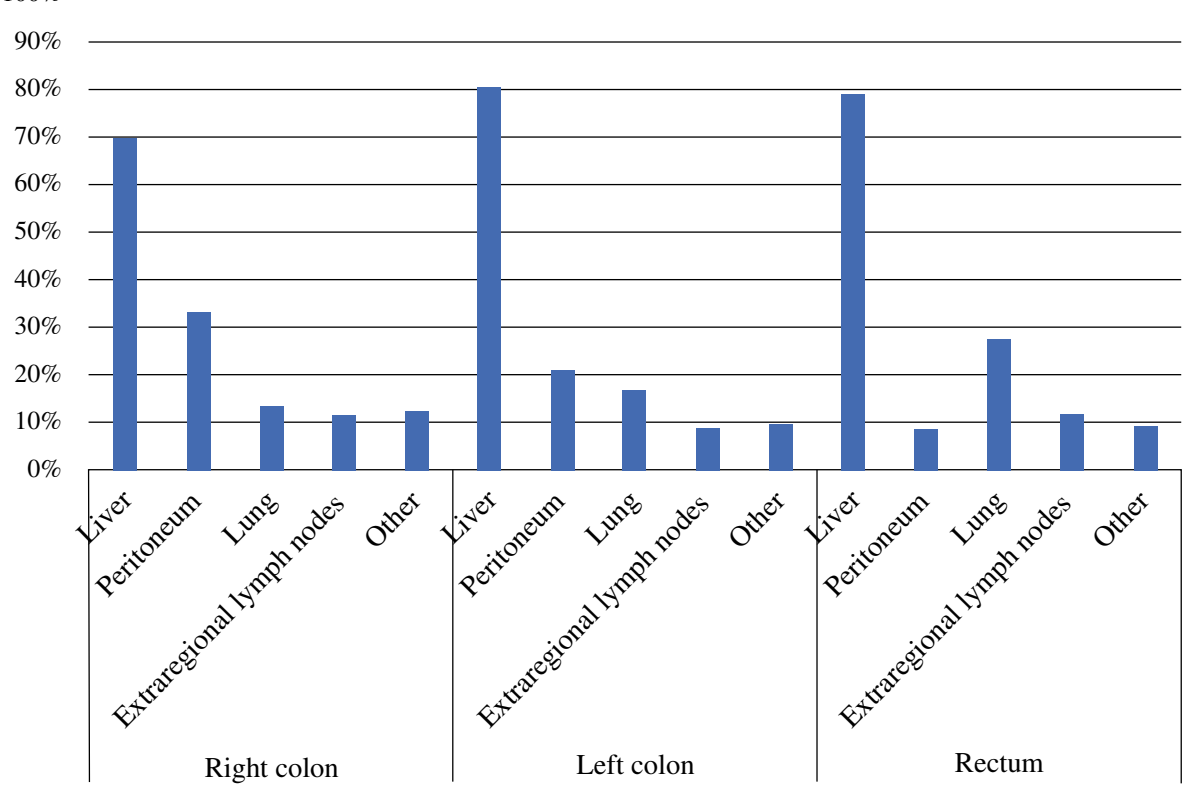

(B)

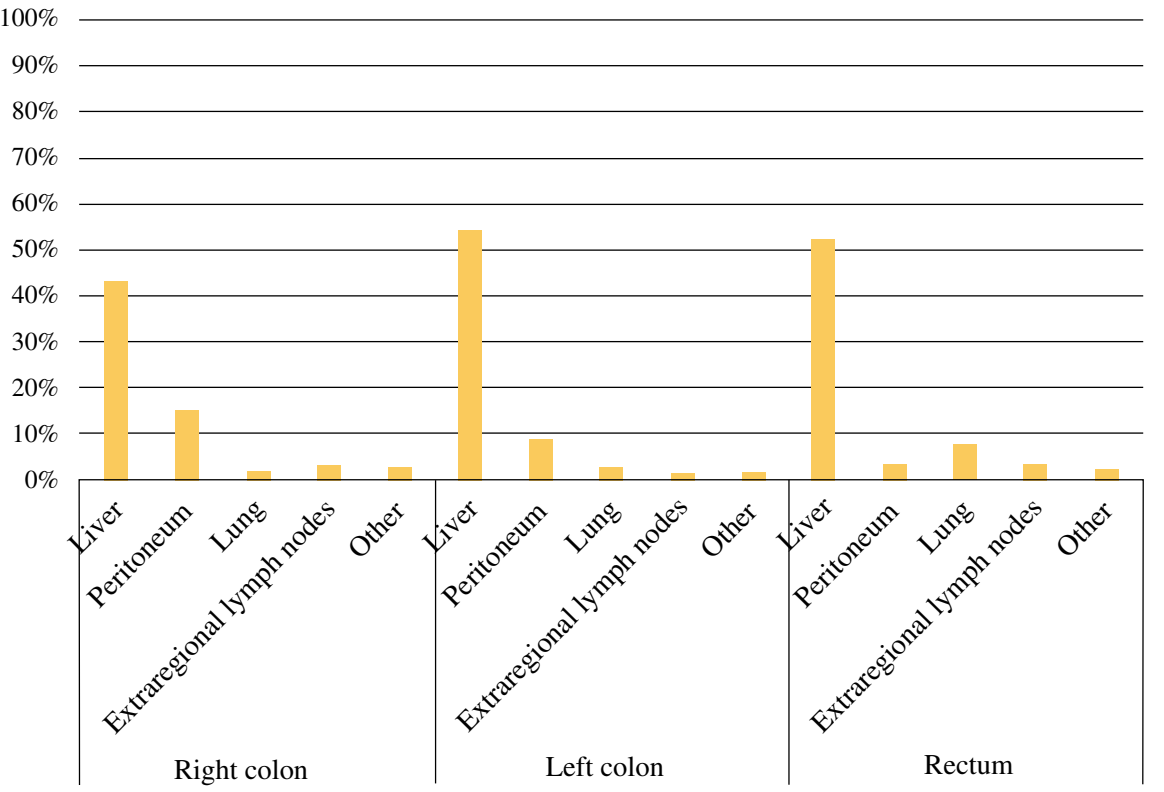

Metastatic spread

Only single metastatic sites

Metastatic spread

All combinations of metastatic sites

Rectum metastasis were excluded. For patients diagnosed with synchronous $\mathrm{mCRC}$ at multiple moments in time, only the first diagnosed CRC was included in the current analysis. In case of synchronous multiple CRC, the tumor with the most aggressive tumor characteristics was used.

Patients were stratified by primary tumor location: right colon (proximal to the splenic flexure), left colon (splenic flexure to rectum), and rectum. Patients' vital status was obtained by linking the NCR to the Municipal Personal
Records Database. Follow-up was completed until January $1,2018$.

\section{Statistical Analyses}

Patient and tumor characteristics were analyzed per primary tumor location. Because $\mathrm{cN}$ is not a reliable parameter for lymph node stage, only (y)pT- and (y)pNstage were presented for patients who underwent surgery. ${ }^{13}$ 


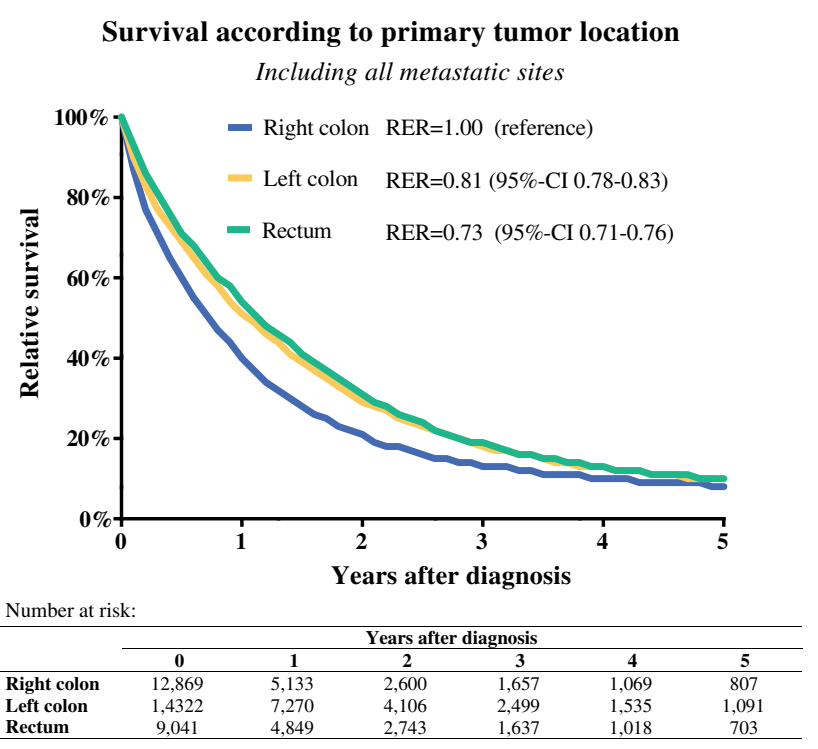

FIG. 2 Relative survival including all metastatic sites, stratified to primary tumor location. Multivariable excess risks (RER) for death after diagnosis of synchronous mCRC are also presented (variables included in the model were location primary tumor, gender, age, morphology, period of diagnosis, resection of the primary tumor, chemotherapy, metastasectomy, and radiotherapy)

Differences in dichotomous outcomes were assessed using the $\chi^{2}$ test. The sites of metastases per primary tumor location were analyzed both for single sites of metastases as well as for overall metastatic sites.

Age standardized relative survival was calculated for all patients stratified to primary tumor location, as the ratio of the survival observed among the CRC patients and the survival that would have been expected based on age, gender, and year of the corresponding general population (Pohar Perme method). Using relative survival, multivariable relative excess risks (RER) were estimated with $95 \%$ confidence intervals (CI) to determine the association between risk of death and primary tumor location. Second, relative survival was calculated for patients with a single site of metastasis (liver, peritoneum, lung, or extraregional lymph nodes), stratified to primary tumor location, and RERs were estimated per single site of metastasis.

A multivariable logistic regression analysis was applied to determine the association between undergoing a metastasectomy and primary tumor location, for patients with the liver-only metastases. RERs were estimated for patients with liver-only metastases, stratified to patients that underwent metastasectomy or not.

$p$ values $<0.05$ were considered statistically significant. Analyses were performed in STATA (version 13.0, Statcorp LP, College Station, TX) and SPSS Statistics for Windows (version 22.0).

\section{RESULTS}

Between 1989 and 2014, a total of 36,297 patients were diagnosed with synchronous mCRC in the Netherlands (Table 1). There were 12,889 patients with RCC, 14,355 with LCC, and 9053 with rectal cancer. The majority of rectal cancer patients was male (62\%), compared with 52\% in RCC and $38 \%$ in LCC. Mucinous and signet-ring adenocarcinoma were most common in RCC, with $16 \%$ and $3 \%$ respectively versus $10 \%$ and $1 \%$ in LCC, and $6 \%$ and $1 \%$ in rectal cancer.

\section{Locations of Synchronous Metastases}

Metastatic sites differed between primary tumor locations (Fig. 1). Lung metastases were most common in rectal cancer patients (28\% vs. $14 \%$ in RCC patients $(p<0.001)$ and $17 \%$ in LCC patients $(p<0.001))$. Liveronly metastases were found in $43 \%, 54 \%$, and $52 \%$ for RCC, LCC, and rectal cancer patients, respectively $(p<0.001)$. The peritoneum was the solitary metastatic site in $15 \%, 9 \%$, or $4 \%$ of patients with RCC, LCC, or rectal cancer respectively $(p<0.001)$.

\section{Relative Survival, Including All Patients} with Synchronous $m C R C$

RCC had worse 1-year relative survival of $40 \%$ compared with $51 \%$ for LCC and $54 \%$ for rectal cancer (Fig. 2). RERs for death also are shown after correction for location of the primary tumor, gender, age, morphology, period of diagnosis, resection of the primary tumor, chemotherapy, metastasectomy, and radiotherapy. The relative survival was significantly worse for RCC compared with LCC (RER $0.81,95 \%$ CI $0.78-0.83$ ) and rectal cancer (RER 0.73, 95\% CI 0.71-0.76).

\section{Relative Survival per Solitary Metastatic Site}

To exclude the possible biases of multiple metastatic sites, patients with solitary metastatic sites were analyzed for survival. The results are depicted in Fig. 3. For patients with liver-only metastases, 1-year relative survival was $43 \%, 57 \%$, and $60 \%$ for RCC, LCC, and rectal cancer respectively. RCC patients had a significantly worse relative survival compared with LCC (RER 0.79, 95\% CI $0.76-0.82$ ) and rectal cancer patients (RER $0.74,95 \%$ CI 0.70-0.77; Table 2).

RCC patients with extraregional lymph nodes as the single site of metastasis had a worse relative survival compared with LCC (RER 0.78, 95\% CI 0.65-0.94) and 


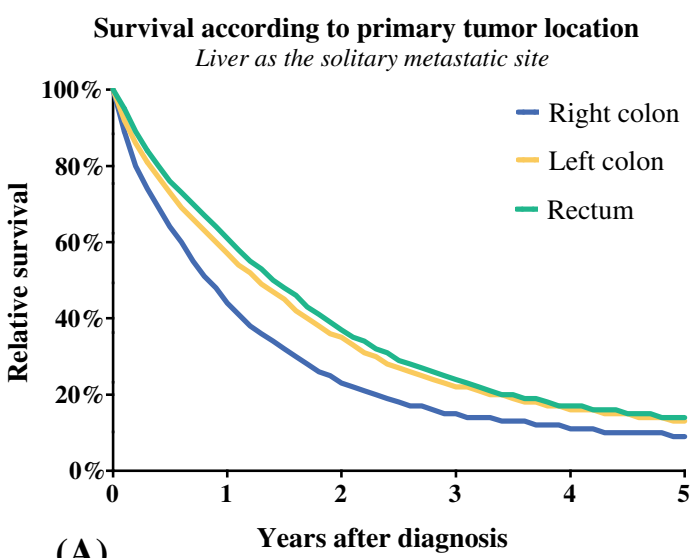

(A)

Number at risk:

\begin{tabular}{lcccccc}
\hline & \multicolumn{7}{c}{ Years after diagnosis } \\
\cline { 2 - 7 } & $\mathbf{0}$ & $\mathbf{1}$ & $\mathbf{2}$ & $\mathbf{3}$ & $\mathbf{4}$ & $\mathbf{5}$ \\
\hline Right colon & 5,579 & 2,387 & 1,225 & 766 & 511 & 367 \\
Left colon & 7,779 & 4,330 & 2,552 & 1,612 & 1,048 & 760 \\
Rectum & 4,742 & 2,806 & 1,689 & 1,052 & 673 & 490 \\
\hline
\end{tabular}

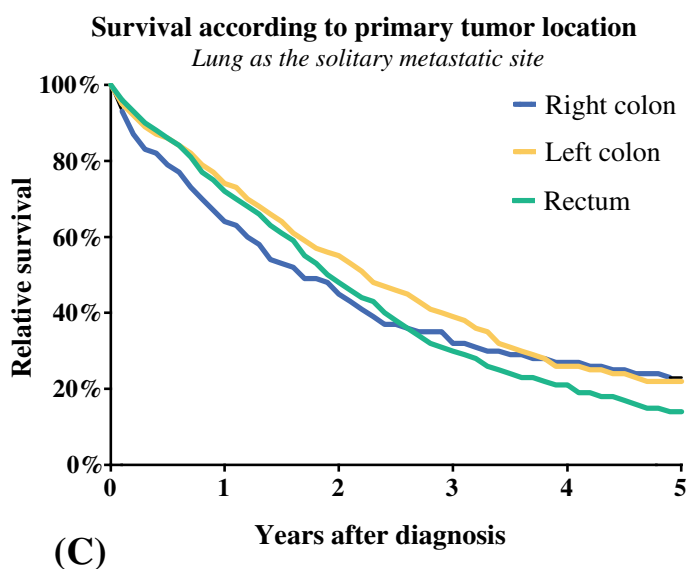

Number at risk:

\begin{tabular}{lcccccc}
\hline & \multicolumn{7}{c}{ Years after diagnosis } \\
\cline { 2 - 7 } & $\mathbf{0}$ & $\mathbf{1}$ & $\mathbf{2}$ & $\mathbf{3}$ & $\mathbf{4}$ & $\mathbf{5}$ \\
\hline Right colon & 281 & 173 & 117 & 79 & 52 & 41 \\
Left colon & 445 & 316 & 224 & 153 & 85 & 59 \\
Rectum & 701 & 487 & 313 & 190 & 117 & 66 \\
\hline
\end{tabular}

FIG. 3 Relative survival for patients with a solitary metastatic site. Survival was analyzed per metastatic site and stratified to primary tumor location. a Patients with liver-only metastases. b Patients with

rectal cancer patients (RER 0.70, 95\% CI 0.55-0.88). Differences in survival for patients with peritoneal or pulmonary metastases were less pronounced, with RERs that did not differ significantly.

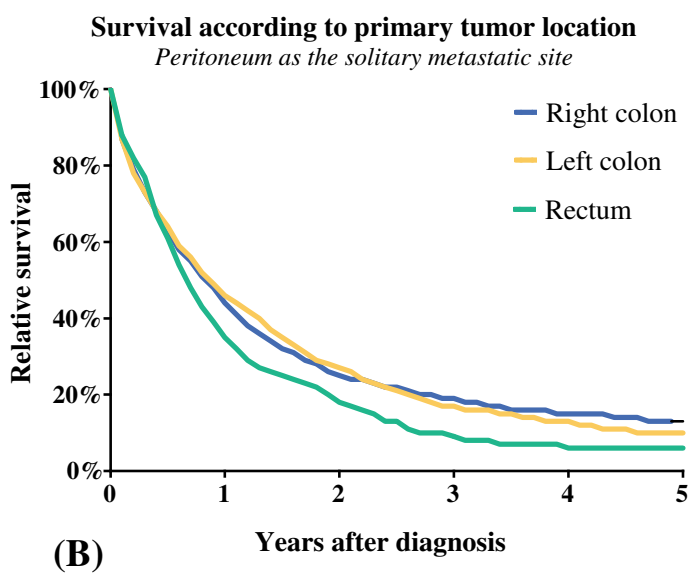

Number at risk:

\begin{tabular}{lcccccc}
\hline & \multicolumn{6}{c}{ Years after diagnosis } \\
\cline { 2 - 7 } & $\mathbf{0}$ & $\mathbf{1}$ & $\mathbf{2}$ & $\mathbf{3}$ & $\mathbf{4}$ & $\mathbf{5}$ \\
\hline Right colon & 1,971 & 851 & 469 & 343 & 244 & 185 \\
Left colon & 1,258 & 564 & 319 & 193 & 128 & 88 \\
Rectum & 320 & 109 & 56 & 26 & 16 & 14 \\
\hline
\end{tabular}

Survival according to primary tumor location Extraregional lymph nodes as the solitary

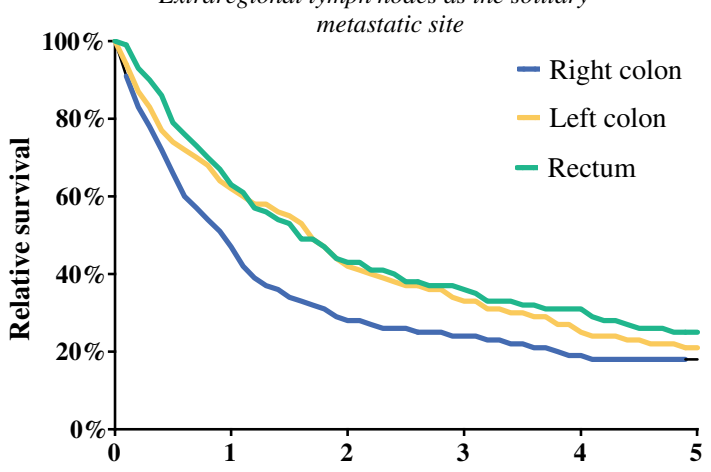

(D)

Years after diagnosis

Number at risk:

\begin{tabular}{lcccccc}
\hline & \multicolumn{7}{c}{ Years after diagnosis } \\
\cline { 2 - 7 } & $\mathbf{0}$ & $\mathbf{1}$ & $\mathbf{2}$ & $\mathbf{3}$ & $\mathbf{4}$ & $\mathbf{5}$ \\
\hline Right colon & 412 & 188 & 111 & 93 & 53 & 39 \\
Left colon & 254 & 153 & 102 & 79 & 50 & 34 \\
Rectum & 318 & 196 & 131 & 106 & 78 & 57 \\
\hline
\end{tabular}

the peritoneum as solitary metastatic site. c Patients with the lung solitary metastatic site. d Patients with extraregional lymph nodes as solitary metastatic sites

\section{Patients with Liver-Only Metastases}

Patients with RCC had a lower chance of undergoing a metastasectomy compared with patients with LCC (OR $1.27,95 \%$ CI 1.13-1.43) or rectal cancer (OR 1.20, 95\% CI 0.99-1.45; Table 3). In Table 4, RERs are presented for 


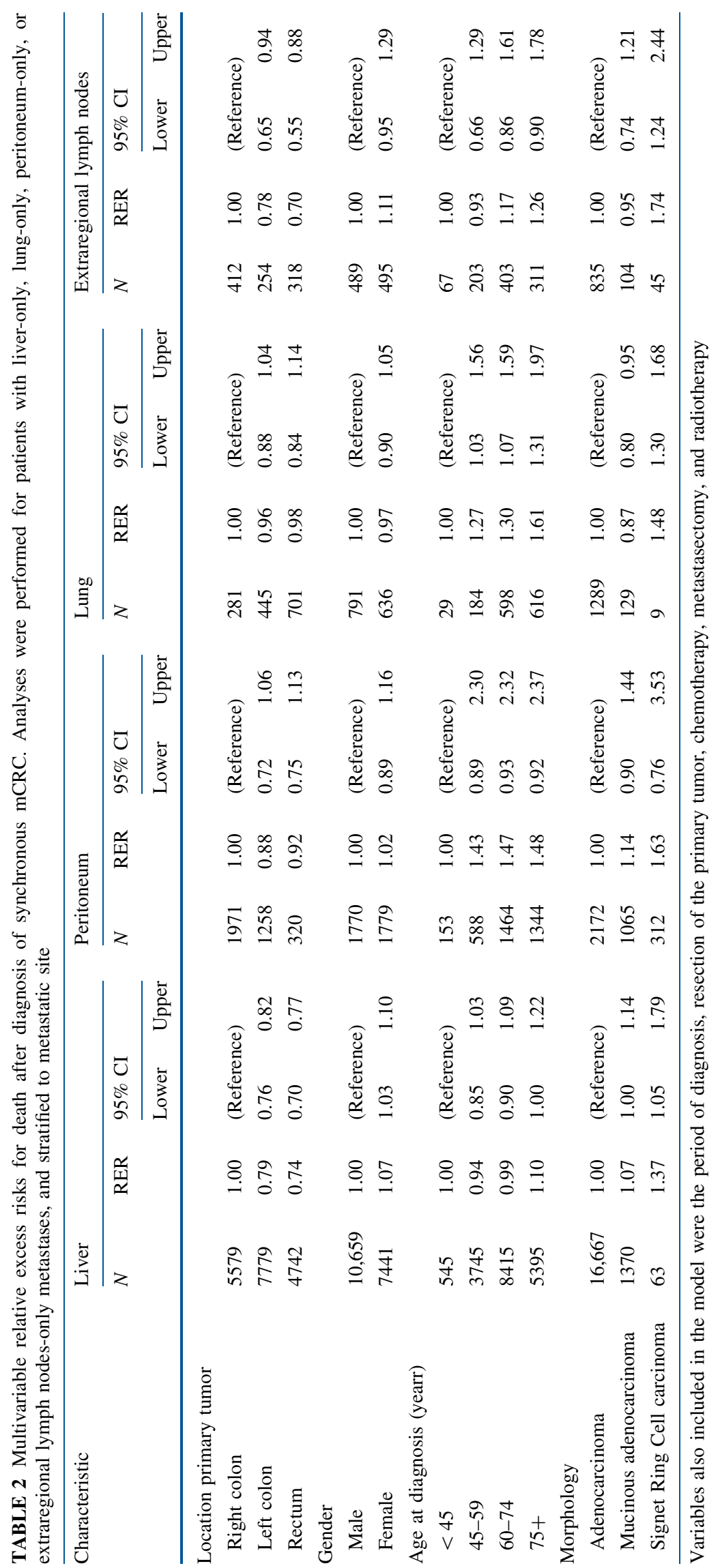


TABLE 3 Logistic regression for the chance of undergoing a metastasectomy in patients with liver-only metastases

\begin{tabular}{|c|c|c|c|c|}
\hline \multirow[t]{3}{*}{ Characteristic } & \multicolumn{4}{|c|}{ Liver-only metastases } \\
\hline & \multirow[t]{2}{*}{$N$} & \multirow[t]{2}{*}{ OR } & \multicolumn{2}{|c|}{$(95 \% \mathrm{CI})$} \\
\hline & & & Lower & Upper \\
\hline \multicolumn{5}{|l|}{ Location primary tumor } \\
\hline Right colon & 5586 & 1.00 & \multicolumn{2}{|c|}{ (Reference) } \\
\hline Left colon & 7802 & 1.27 & 1.13 & 1.43 \\
\hline Rectum & 4747 & 1.20 & 0.99 & 1.45 \\
\hline \multicolumn{5}{|l|}{ Gender } \\
\hline Male & 10,678 & 1.00 & \multicolumn{2}{|c|}{ (Reference) } \\
\hline Female & 7457 & 0.95 & 0.86 & 1.05 \\
\hline \multicolumn{5}{|l|}{ Age (yr) } \\
\hline$<45$ & 546 & 1.00 & \multicolumn{2}{|c|}{ (Reference) } \\
\hline $45-59$ & 3748 & 0.73 & 0.56 & 0.95 \\
\hline $60-74$ & 8428 & 0.53 & 0.41 & 0.69 \\
\hline$\geq 75$ & 5413 & 0.20 & 0.15 & 0.27 \\
\hline \multicolumn{5}{|l|}{ Morphology } \\
\hline Adenocarcinoma & 16,698 & 1.00 & \multicolumn{2}{|c|}{ (Reference) } \\
\hline Mucinous adenocarcinoma & 1374 & 0.90 & 0.75 & 1.08 \\
\hline Signet Ring Cell Carcinoma & 63 & 0.77 & 0.31 & 1.94 \\
\hline
\end{tabular}

Variables also included in the model were the period of diagnosis, resection of the primary tumor, chemotherapy, metastasectomy, and radiotherapy patients with liver-only metastases, stratified for metastasectomy status. In both groups, patients with RCC showed worse survival compared with LCC.

\section{DISCUSSION}

In this large population-based study, primary tumor location was identified as an independent prognostic factor for relative survival. Also, the frequency of different metastatic sites varied based on primary tumor location. These results support the notion that RCC, LCC, and rectal cancer should be regarded as separate entities.

Patients with RCC had a significantly worse 1-year relative survival of $40 \%$ compared with more than $50 \%$ for patients with LCC and rectal cancer. In patients with liveronly metastases, the relative survival remained significantly worse for RCC compared with LCC and rectal cancer. These differences in survival are in line with previous reports, suggesting a prognostic impact of primary tumor location in mCRC. ${ }^{4,10,14,15}$ However, timing of metastatic disease, by the distinction of metachronous or synchronous mCRC, is a prognostic factor as well. ${ }^{16}$ Unfortunately, most previous studies made no clear distinction between synchronous and metachronous metastases in their analyses. ${ }^{4,8,15}$ Therefore, the current study adds new information on the significance of primary tumor location in synchronous mCRC patients.
TABLE 4 Multivariable relative excess risks for death after diagnosis of synchronous mCRC. Patients with liver-only metastases were selected and stratified to undergoing metastasectomy or not

\begin{tabular}{|c|c|c|c|c|c|c|c|c|}
\hline \multirow[t]{3}{*}{ Characteristic } & \multicolumn{4}{|c|}{ No metastasectomy } & \multicolumn{4}{|c|}{ Metastasectomy } \\
\hline & \multirow[t]{2}{*}{$N$} & \multirow[t]{2}{*}{ RER } & \multicolumn{2}{|c|}{$95 \% \mathrm{CI}$} & \multirow[t]{2}{*}{$N$} & \multirow[t]{2}{*}{ RER } & \multicolumn{2}{|c|}{$95 \% \mathrm{CI}$} \\
\hline & & & Lowe & Upper & & & Lowe & Upper \\
\hline \multicolumn{9}{|l|}{ Location primary tumor } \\
\hline Right colon & 4901 & 1.00 & \multicolumn{2}{|c|}{ (Reference) } & 678 & 1.00 & \multicolumn{2}{|c|}{ (Reference) } \\
\hline Left colon & 6586 & 0.80 & 0.77 & 0.84 & 1193 & 0.66 & 0.57 & 0.76 \\
\hline Rectum & 3823 & 0.73 & 0.70 & 0.77 & 919 & 0.84 & 0.66 & 1.06 \\
\hline \multicolumn{9}{|l|}{ Gender } \\
\hline Male & 8921 & 1.00 & \multicolumn{2}{|c|}{ (Reference) } & 1738 & 1.00 & \multicolumn{2}{|c|}{ (Reference) } \\
\hline Female & 6389 & 1.06 & 1.02 & 1.10 & 1052 & 1.15 & 1.02 & 1.29 \\
\hline \multicolumn{9}{|l|}{ Age (yr) } \\
\hline$<45$ & 405 & 1.00 & \multicolumn{2}{|c|}{ (Reference) } & 140 & 1.00 & \multicolumn{2}{|c|}{ (Reference) } \\
\hline $45-59$ & 2958 & 0.95 & 0.85 & 1.05 & 787 & 0.90 & 0.70 & 1.16 \\
\hline $60-74$ & 6936 & 1.01 & 0.91 & 1.13 & 1479 & 0.87 & 0.68 & 1.11 \\
\hline $75+$ & 5011 & 1.10 & 0.99 & 1.22 & 384 & 0.96 & 0.71 & 1.29 \\
\hline \multicolumn{9}{|l|}{ Morphology } \\
\hline Adenocarcinoma & 14,079 & 1.00 & \multicolumn{2}{|c|}{ (Reference) } & 2588 & 1.00 & \multicolumn{2}{|c|}{ (Reference) } \\
\hline Mucinous adenocarcinoma & 1174 & 1.07 & 1.00 & 1.14 & 196 & 1.07 & 0.86 & 1.34 \\
\hline Signet ring cell carcinoma & 57 & 1.36 & 1.03 & 1.79 & 6 & 1.52 & 0.54 & 4.27 \\
\hline
\end{tabular}

Variables also included in the model were period of diagnosis, resection of the primary tumor, chemotherapy, metastasectomy, and radiotherapy 
The explanation for the differences in survival according to the primary tumor locations is most likely multifactorial. A part of this explanation is the difference in metastatic sites, as observed in relation to primary tumor location. These findings are consistent with previous epidemiologic research that indicates a relationship between primary tumor location and metastatic location. ${ }^{17-19}$ The results presented in the current paper add valuable information, because previous publications are limited by their relatively small sample size, grouping together of metachronous and synchronous metastases, or the absence of several sites of metastasis. ${ }^{19}$ The differences in metastatic sites can be explained by several hypotheses. ${ }^{17,18,20}$ First, there is the seed-and-soil hypothesis, which states that tumor metastases have a preference for specific organs (e.g., the liver), based on interactions between tumor cells and their microenvironment. ${ }^{21}$ New insights, such as metastatic gene signatures and tumor-stroma interactions at a molecular level, have further refined this hypothesis. ${ }^{22}$ Previously, data from an autopsy study, including more than 1500 patients with metastatic CRC demonstrated significant differences in metastatic sites between histological subtypes, with a higher rate of peritoneal metastasis as well as multiple sites of metastasis for both mucinous and signet ring cell adenocarcinoma. ${ }^{9}$ In the current study, we observed a higher prevalence of mucinous and signet ring cell adenocarcinoma for RCC, yielding a possible explanation for the higher rate of peritoneal metastases in RCC. Second, distinct vascular drainage systems explain, according to the hemodynamic hypothesis, different metastatic sites. This is most evident for the increased numbers of lung metastases derived from the rectum, because venous drainage of the rectum bypasses the portal system and encounters the central circulation first. ${ }^{2,18,19}$ The differences in metastatic sites could be partly responsible for differences in survival between primary tumor locations. Peritoneal metastases, which are associated with poor survival, were more commonly found for RCC. ${ }^{23}$ Liver and pulmonary metastases, which can potentially be treated with curative intent, were more prevalent in LCC and rectal cancer.

However, the difference in metastatic sites is not the only factor that explains the prognostic difference observed between RCC, LCC, and rectal cancer, because survival differences persisted when patients with liver-only metastases were selected. In this group, RCC patients less frequently underwent surgical resection, maybe because of a higher tumor load. It has been suggested that the relative delay in diagnosis of RCC is at least partly responsible for this. ${ }^{14,24,25}$
Still, the difference in survival remained present even when only patients with metastasectomy were selected. This suggests that underlying biology of RCC differs from LCC and rectal cancer, with increased numbers of cases with BRAF mutations and KRAS mutations. ${ }^{8,15,26}$

Data in this study were derived from the NCR which is known for its high-quality data and complete registration. We aimed to minimize selection bias by selecting all patients with synchronous mCRC in the Netherlands, hereby representing daily practice. There are, however, several limitations that should be addressed. The major limitation of this retrospective study was, as in most population-based studies, the absence of information on certain patient and tumor characteristics. First, the NCR did not register data on comorbidity, performance status, and details of treatment regimens during our study period, which may have differed between primary tumor sites, thereby influencing survival outcomes. Second, and possibly most importantly, data on molecular profiling was lacking while previous studies showed significant differences in molecular profiles between primary tumor sites. Analyses of mutational profiles even suggest that the current right/left classification may not fully recapitulate regional variations in tumor biology. ${ }^{27}$ Because data on mutational profiles were lacking in the current study, it is impossible to state anything to this extend.

\section{CONCLUSIONS}

We showed significant differences in relative survival between synchronous metastasized RCC, LCC, and rectal cancer, which can be partly explained by the distinct metastatic sites, and are also likely to be caused by differences in tumor biology. These findings support the concept that primary tumor location should be regarded as a prognostic factor in synchronous mCRC and emphasizes its implication for clinical practice. Future trials on the effect of chemotherapy should be stratified to primary tumor location, because it is likely to effect the therapeutic response.

DISCLOSURE Ignace H.J.T. de Hingh has received a research grants from Roche and QPS/RandD. Rob H.A. Verhoeven has received grant from Roche and Bristol-Myers Squibb to his institute. The other authors have no disclosures.

OPEN ACCESS This article is distributed under the terms of the Creative Commons Attribution 4.0 International License (http://crea tivecommons.org/licenses/by/4.0/), which permits unrestricted use, distribution, and reproduction in any medium, provided you give appropriate credit to the original author(s) and the source, provide a link to the Creative Commons license, and indicate if changes were made. 


\section{REFERENCES}

1. Ferlay J, Soerjomataram I, Dikshit R, et al. Cancer incidence and mortality worldwide: sources, methods and major patterns in GLOBOCAN 2012. Int J Cancer. 2015;136(5):E359-86.

2. van der Geest LG, Lam-Boer J, Koopman M, Verhoef C, Elferink MA, de Wilt JH. Nationwide trends in incidence, treatment and survival of colorectal cancer patients with synchronous metastases. Clin Exp Metastasis. 2015;32(5):457-65.

3. Brouwer NPM, Bos A, Lemmens V, et al. An overview of 25 years of incidence, treatment and outcome of colorectal cancer patients. Int J Cancer. 2018;143:2758.

4. van Erning FN, Elferink MA, Bos AC, Lemmens VE. RE: primary tumor location as a prognostic factor in metastatic colorectal cancer. J Natl Cancer Inst. 2015;107(9):1.

5. Cremolini C, Antoniotti C, Lonardi S, et al. Primary tumor sidedness and benefit from FOLFOXIRI plus bevacizumab as initial therapy for metastatic colorectal cancer. Ann Oncol. 2018;29:1528.

6. Holch JW, Ricard I, Stintzing S, Modest DP, Heinemann V. The relevance of primary tumour location in patients with metastatic colorectal cancer: a meta-analysis of first-line clinical trials. Eur J Cancer. 2017;70:87-98.

7. Boeckx N, Koukakis R, Op de Beeck K, et al. Effect of primary tumor location on second- or later-line treatment outcomes in patients with RAS wild-type metastatic colorectal cancer and all treatment lines in patients with RAS mutations in four randomized panitumumab studies. Clin Colorectal Cancer. 2018;17(3):170-8.e173.

8. Petrelli F, Tomasello G, Borgonovo K, et al. Prognostic survival associated with left-sided vs right-sided colon cancer: a systematic review and meta-analysis. JAMA Oncol. 2016;3:211.

9. Hugen N, van de Velde CJ, de Wilt JH, Nagtegaal ID. Metastatic pattern in colorectal cancer is strongly influenced by histological subtype. Ann Oncol. 2014;25(3):651-7.

10. van Gestel YR, de Hingh IH, van Herk-Sukel MP, et al. Patterns of metachronous metastases after curative treatment of colorectal cancer. Cancer Epidemiol. 2014;38(4):448-54.

11. Fritz A, Percy C, Jack A, et al. International classification of diseases for oncology (ICD-O). Geneva: World Health Organization; 2000.

12. Wittekind CGF, Hutter R, Klimpfinger MLS. TNM atlas. Berlin: Springer; 2004.

13. Brouwer NPM, Stijns RCH, Lemmens VEPP, et al. Clinical lymph node staging in colorectal cancer; a flip of the coin? Eur $J$ Surg Oncol. 2018;44:1241.

14. Price TJ, Beeke C, Ullah S, et al. Does the primary site of colorectal cancer impact outcomes for patients with metastatic disease? Cancer. 2015;121(6):830-5.
15. Loupakis F, Yang D, Yau L, et al. Primary tumor location as a prognostic factor in metastatic colorectal cancer. $J$ Natl Cancer Inst. 2015;107(3):1.

16. Kumar R, Price TJ, Beeke C, et al. Colorectal cancer survival: an analysis of patients with metastatic disease synchronous and metachronous with the primary tumor. Clin Colorectal Cancer. 2014;13(2):87-93.

17. Amri R, Bordeianou LG, Sylla P, Berger DL. Variations in metastasis site by primary location in colon cancer. J Gastrointest Surg. 2015;19(8):1522-7.

18. Riihimaki M, Hemminki A, Sundquist J, Hemminki K. Patterns of metastasis in colon and rectal cancer. Sci Rep. 2016;6:29765.

19. Robinson JR, Newcomb PA, Hardikar S, Cohen SA, Phipps AI. Stage IV colorectal cancer primary site and patterns of distant metastasis. Cancer Epidemiol. 2017;48:92-95.

20. He XK, Wu W, Ding YE, Li Y, Sun LM, Si J. Different anatomical subsites of colon cancer and mortality: a populationbased study. Gastroenterol Res Pract. 2018;2018:7153685.

21. Ribatti D, Mangialardi G, Vacca A. Stephen Paget and the 'seed and soil' theory of metastatic dissemination. Clin Exp Med. 2006;6(4):145-9.

22. Sun C, Zargham R, Shao Q, et al. Association of CD98, integrin beta1, integrin beta3 and Fak with the progression and liver metastases of colorectal cancer. Pathol Res Pract. 2014;210(10):668-74.

23. Hugen N, Nagtegaal ID. Distinct metastatic patterns in colorectal cancer patients based on primary tumour location. Eur J Cancer. 2017;75:3-4.

24. Engstrand J, Nilsson H, Stromberg C, Jonas E, Freedman J. Colorectal cancer liver metastases - a population-based study on incidence, management and survival. BMC Cancer. 2018;18(1):78.

25. Noren A, Eriksson HG, Olsson LI. Selection for surgery and survival of synchronous colorectal liver metastases; a nationwide study. Eur J Cancer. 2016;53:105-14.

26. Goffredo P, Utria AF, Beck AC, et al. The prognostic impact of KRAS mutation in patients having curative resection of synchronous colorectal liver metastases. J Gastrointest Surg. 2018;23:1957.

27. Loree JM, Pereira AAL, Lam M, et al. Classifying colorectal cancer by tumor location rather than sidedness highlights a continuum in mutation profiles and consensus molecular subtypes. Clin Cancer Res. 2018;24(5):1062-72.

Publisher's Note Springer Nature remains neutral with regard to jurisdictional claims in published maps and institutional affiliations. 